\title{
PRODUÇÃO DE UMA CARTILHA EDUCACIONAL SOBRE FOSSAS SÉPTICAS
}

\author{
Amarildo Otávio Martins ${ }^{1}$ \\ Elisângela Silva Lopes Ricardo² \\ Hélvio Silvester Andrade de Sousa ${ }^{3}$ \\ Priscila Lemke ${ }^{4}$ \\ Vanessa de Souza ${ }^{5}$
}

Resumo: O sistema de fossa séptica-filtro é um tratamento de esgoto doméstico que ocorre pela ação de microrganismos, que são responsáveis pela decomposição da matéria orgânica. Foi desenvolvido uma cartilha educacional com relação ao conceito, funcionamento e manutenção das fossas sépticas e filtros anaeróbios, elaborada por estudantes do IFC, utilizando um programa de design gráfico. A cartilha complementa as políticas públicas de saneamento na cidade de Pomerode (SC), que através de um Diagnóstico Amostral identificou que $91,70 \%$ da população utiliza o tratamento unifamiliar de esgoto doméstico através do sistema de Fossa Séptica e filtro anaeróbio; ressaltando a importância da elaboração da cartilha educacional.

Palavras-chave: Cartilha Educacional; Fossa Séptica; Saúde Pública; Educação Ambiental.

Abstract: The septic tank-filter system is a treatment of domestic sewage that occurs through the action of microorganisms, which are responsible for the decomposition of organic matter. An educational booklet was developed regarding the concept, operation and maintenance of septic tanks and anaerobic filters, prepared by IFC students, using a graphic design program. The booklet is in line with public sanitation policies in the city of Pomerode (SC, Brazil), which through a Sample Diagnosis identified that $91.70 \%$ of the population uses the single-family treatment of domestic sewage through the septic tank system and anaerobic filter; highlighting the importance of preparing the educational booklet.

Keywords: Educational Booklet; Septic Tank; Public Health; Environmental Education.

\footnotetext{
${ }^{1}$ Universidade Federal de Santa Catarina. E-mail: amarildo.martins@ufsc.br.

2 Instituto Federal Catarinense - Campus Blumenau. E-mail: elisangela.ricardo@ifc.edu.br.

${ }^{3}$ Instituto Federal Catarinense - Campus Blumenau. E-mail: helvio.sousa@ifc.edu.br.

${ }^{4}$ Instituto Federal Catarinense - Campus Blumenau. E-mail: priscila523lemke@gmail.com

${ }^{5}$ Instituto Federal Catarinense - Campus Blumenau. E-mail: vanessadesouza020403@gmail.com
} 


\section{Introdução}

O esgoto doméstico provém principalmente de residências, estabelecimentos comerciais, instituições ou edificações que dispõe de instalações hídricas envolvendo banheiros, lavanderias e cozinhas (FUNASA, 2004); a construção de fossas sépticas é sugerida na ausência de sistemas públicos de coleta e tratamento de esgotos domésticos; portanto ações que promovam o conhecimento e melhoria no processo de tratamento de efluentes estão diretamente relacionadas com o bem-estar e a saúde pública.

$O$ século $X X$ assistiu à redução significativa da morbimortalidade por doenças infecciosas, resultado da melhoria da alimentação, educação e de medidas como a vacinação e o saneamento básico. No entanto, atualmente a carência de investimentos no saneamento básico no Brasil está relacionada a um dos principais fatores no número de mortes de crianças de 1 mês a 1 ano de idade segundo o relatório do Ministério da Saúde de 2018 (MINISTÉRIO DA SAÚDE, 2019) junto ao Departamento de Vigilância de Doenças e Agravos não Transmissíveis e Promoção da Saúde.

A lei de № 14.026,2020 define o Marco Legal do Saneamento Básico (BRASIL, 2020) está relacionada aos problemas do saneamento básico e políticas públicas, onde considera-se como serviço público para o esgotamento sanitário a disposição final originária de tratamentos coletivos ou individuais, incluindo as fossas sépticas de forma ambientalmente adequadas.

O Marco Legal do Saneamento redefine os contratos de prestação dos serviços públicos de saneamento básico que deverão atingir metas de universalização que garantam o atendimento de $99 \%$ (noventa e nove por cento) da população brasileira com água potável e de $90 \%$ (noventa por cento) da população com coleta e tratamento de esgotos até 31 de dezembro de 2033, proporcionando investimentos significativos nos setores públicos e privados bem como promover a Educação Ambiental em todos os níveis de formação.

Estudos apontam retornos favoráveis para a economia em função de investimentos em saneamento, tanto em Estações de Tratamento de Efluentes (E.T.E.) bem como em sistemas individuais envolvendo a construção de fossas sépticas se comparados às despesas em saúde pública (DA COSTA, 2014); podendo reduzir cerca de 250 mortes com cerca de 5,5 milhões de infecções intestinais, bem como reduzir a poluição dos cursos d'água em cerca de 130 mil toneladas de resíduos por ano.

A maioria dos municípios brasileiros se observa a formação de núcleos populacionais próximos a córregos e rios, os quais são utilizados para obtenção da água para consumo e para direcionar seus efluentes, paralelamente o processo de urbanização acelerado e não planejado com intensa degradação dos recursos naturais, ameaça a sustentabilidade e a qualidade ambiental (DE VICQ.; PRAÇA LEITE, 2020).

Dependendo das características do efluente doméstico lançado in natura em águas superficiais, o mesmo pode sofrer um processo de autodepuração,

revista brasileira educação ambiental 
que através de transformações físicas, químicas e biológicas produzem compostos de menor complexidade e toxicidade permitindo a assimilação desses dejetos pelo meio líquido. No entanto, quando lançado em quantidade superior à capacidade de assimilação do corpo d'água receptor (MARTINS, 2018) ocorre um desequilíbrio dinâmico no meio ambiente.

O sistema de fossa séptica-filtro é um sistema de tratamento do esgoto doméstico através da biodigestão, relacionado à ação de microrganismos, (EMBRAPA, 2014) que são os responsáveis pela decomposição e redução da carga orgânica presente em grande quantidade no esgoto doméstico. O tratamento na fossa séptica consiste em um tanque que faz a separação entre a parte sólida e a parte líquida do esgoto, por meio da sedimentação; onde a parte líquida é direcionada para o tanque do filtro anaeróbio. Nesse sentido, o processo de tratamento por fossa séptica, é uma saída economicamente viável para localidades sem acesso ao tratamento coletivo de esgoto efetuado por uma E.T.E. (EMBRAPA, 2014) a nível municipal, porém é necessária a participação efetiva da comunidade para que sua implantação alcance os objetivos desejados.

As recomendações sobre a construção e implementação podem ser observadas pela regulamentação da Associação Brasileira de Normas Técnicas Norma 7229 (ABNT 7229,2021) que define o projeto, construção e operação de sistemas de tanques sépticos e Norma 13969 (ABNT 13969, 2021) que complementa a parte referente ao tratamento e disposição dos efluentes de tanques sépticos. No Brasil, segundo o último levantamento realizado pelo Sistema Nacional de Informações sobre Saneamento (SNIS, 2019) $53 \%$ dos brasileiros têm acesso à coleta de esgoto, e com relação ao tratamento $46 \%$ do esgoto tratado em todo o país. No entanto, de acordo com - SNIS pode-se observar uma grande discrepância por regiões, sendo que na região Norte o tratamento de esgoto chega ao máximo a $21,7 \%$, nordeste $24 \%$, sudeste $50,09 \%$, sul $45,44 \%$ com relação ao tratamento de esgoto.

O município de Pomerode localizado em Santa Catarina na região do médio vale do Itajaí possui uma população estimada em 34.010 (IBGE, 2020), onde o acesso à coleta e tratamento coletivo de esgoto contempla uma pequena parcela da população, sendo que a grande maioria utiliza o tratamento unifamiliar de esgoto doméstico através do sistema de fossa séptica e filtro anaeróbio. O Diagnóstico Amostral, no município de Pomerode possibilitou identificar que $91,70 \%$ da população amostrada possui sistema de tratamento de esgoto sanitário relacionado à presença de fossas sépticas.

Durante o ano de 2018 o município de Pomerode realizou um Diagnóstico Amostral das Residências com Fossa Séptica e Filtro Anaeróbio (FURB et al., 2018), possibilitando obter informações e propor procedimentos para atuação das políticas públicas com relação ao saneamento. O Diagnóstico Amostral gerado através das pesquisas de campo a partir de questionários, possibilitou o levantamento de informações com relação ao sistema de esgoto domiciliar no município. 
A Figura 1 apresenta as informações levantadas no Diagnóstico Amostral dos Sistemas Individuais de Tratamento de Esgoto Doméstico com relação ao percentual de residências que possuem rede coletiva de esgoto e a presença de fossas sépticas.
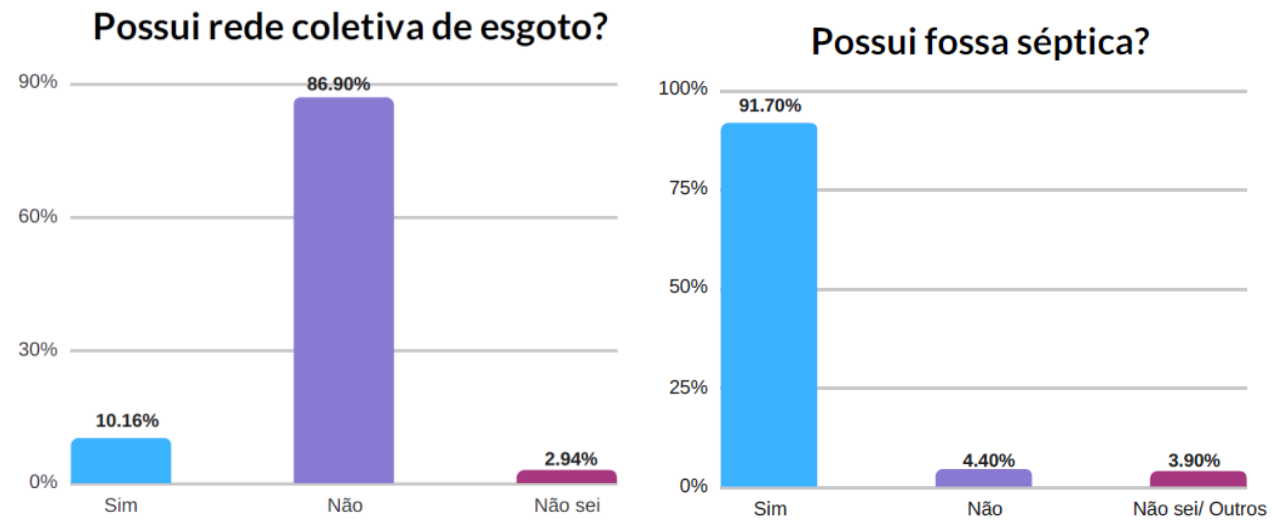

Figura 1: Pergunta do Questionário: Possuem rede coletiva de esgoto e possuem fossa séptica. Fonte: Diagnóstico Amostral dos Sistemas Individuais de Tratamento de Esgoto Doméstico (2018).

Portanto segundo o Diagnóstico Amostral, no município de Pomerode $86,90 \%$ não possui rede coletiva de esgoto, e $91,70 \%$ possuem sistema de tratamento de esgoto sanitário relacionado à presença de fossas sépticas. Com relação à presença de filtro anaeróbio das residências (Figura 2) 82,54\% possuem o sistema em conjunto com as fossas sépticas. Portanto, uma grande maioria utiliza o tratamento de esgoto doméstico através do sistema de Fossa Séptica e filtro anaeróbio.

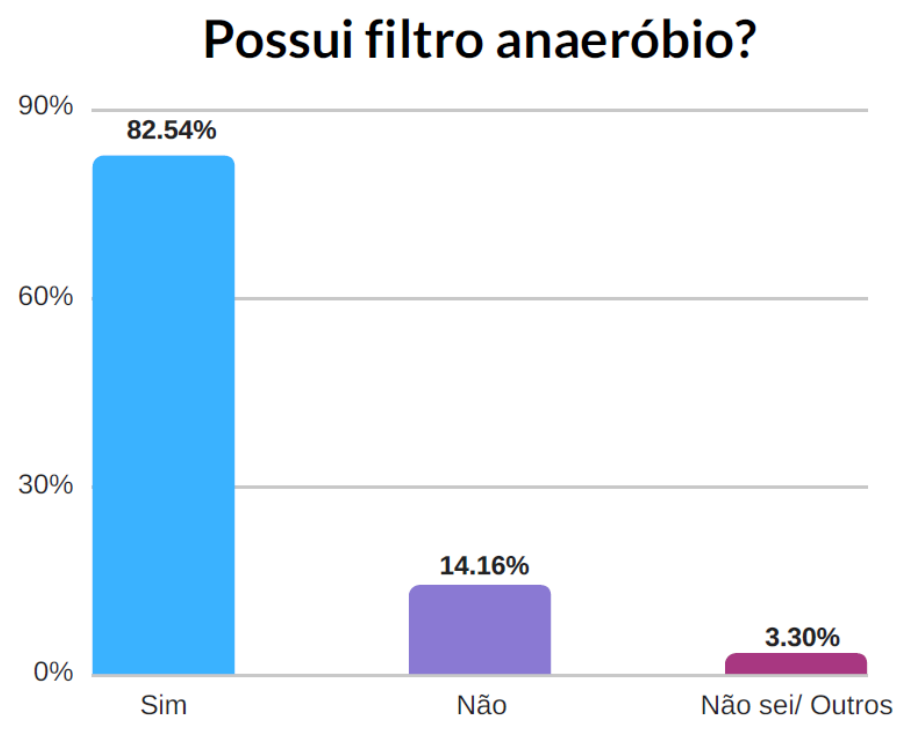

Figura 2: Pergunta do Questionário: Possuem filtro anaeróbio. Fonte: Diagnóstico Amostral dos Sistemas Individuais de Tratamento de Esgoto Doméstico (2018). 
Na Figura 3 o levantamento sobre a realização da limpeza das fossas sépticas e a disposição final com relação ao efluente tratado. Observa-se que a limpeza regular de fossas sépticas é de $51,93 \%$ e mais da metade desse percentual efetua a disposição final do efluente em redes de águas pluviais, rios e córregos.
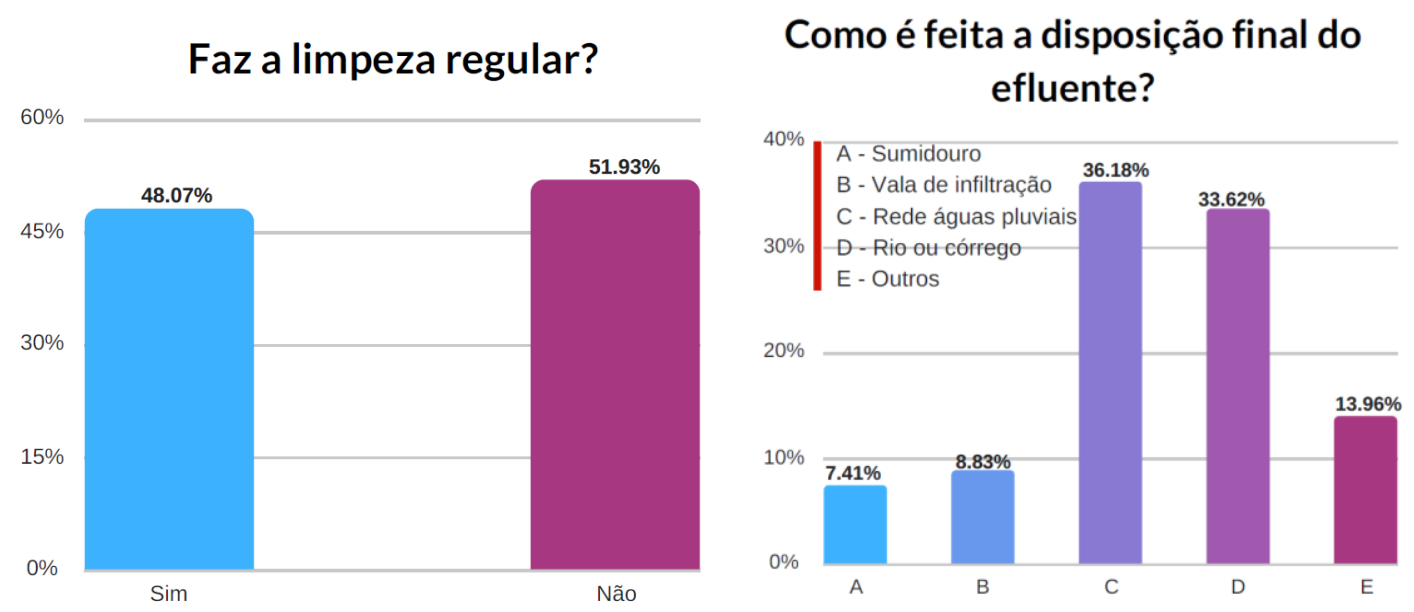

Figura 3: Pergunta do Questionário: Realização da limpeza e a disposição final com relação ao efluente tratado. Fonte: Diagnóstico Amostral dos Sistemas Individuais de Tratamento de Esgoto Doméstico (2018).

Diante da relevância do relatório "Diagnóstico Amostral dos Sistemas Individuais de Tratamento de Esgoto Doméstico" no município de Pomerode e a relação direta do saneamento básico com o bem-estar e a saúde da comunidade é urgente toda ação que promova melhorias no processo de tratamento de efluentes, para que seja alcançado o envolvimento da comunidade, com informações com relação a Educação Ambiental e a consciência da comunidade de modo a levar a formação (FOCESI,1998) e a adoção de comportamentos ambientalmente corretos.

Programas e campanhas educativas, relacionadas ao meio ambiente com a participação das escolas, organizações não governamentais são fundamentais para a formulação e execução de programas e atividades vinculadas a Educação Ambiental (TISCHER, 2016).

Nesse sentido o Instituto Federal Catarinense (campus Blumenau) junto com a Universidade Federal de Santa Catarina produziu a partir do projeto de pesquisa "Avaliação de desempenho do sistema de fossa séptica e filtro anaeróbio, antes e após a limpeza, em residências da cidade de Pomerode" uma Cartilha Educacional com o título "Fossa Séptica e Filtro Anaeróbio: Conceitos e Dicas de Manutenção" segundo as recomendações da NBR 7229; objetivando informar a importância de sistemas de fossas sépticas com a presença de filtros anaeróbios e sumidouros bem como a utilização e manutenção. 


\section{Materiais e Métodos}

O projeto envolveu a elaboração de um material didático no formato de uma cartilha educacional disponível junto ao site do Instituto Federal Catarinense (IFC, 2021); trazendo informações sobre o princípio, funcionamento, instalação e manutenção de sistemas de fossas sépticas acoplados a filtro anaeróbio, com a utilização de um software livre de design gráfico CANVA; objetivado envolver estudantes e a comunidade com relação à Educação Ambiental.

\section{Criação e elaboração do projeto - software CANVA}

A cartilha foi criada por discentes sob a orientação de docentes do IFC e UFSC. Os tópicos abordados na cartilha foram: definição de esgoto; definição e funcionamento do sistema de fossa-filtro; dicas de uso e manutenção do sistema fossa séptica e filtro anaeróbio bem como a importância do tratamento do esgoto para a saúde da comunidade e do meio ambiente.

Em um segundo momento, discussões e práticas de conscientização da cartilha foram feitas através de um questionário contendo perguntas para serem feitas com estudantes matriculados na disciplina de Educação Ambiental do curso de graduação com licenciatura em química junto a UFSC e estudantes do ensino médio do IFC.

Para a elaboração da cartilha, utilizou-se uma plataforma de design gráfico CANVA disponível na forma on-line; a plataforma foi escolhida pela simplicidade de interação gráfica bem como recursos gratuitos e intuitivos, com alguns modelos pré-definidos e sugestivos, o que facilita na elaboração; portanto acessível para alunos e profissionais na área da educação.

Com a escolha da plataforma de design gráfico, os alunos foram envolvidos na elaboração da cartilha, iniciando a manipulação de recursos de design e os diferentes passos na plataforma CANVA envolvendo a edição das caixas de texto, figuras e imagens, relacionadas aos conteúdos do tema da cartilha educacional confeccionada em um total de 15 páginas.

O tema sobre tratamento de efluentes possui informações técnicas e científicas relativamente complexas, no entanto, o objetivo da cartilha é trazer informações onde a sociedade possa ser orientada quanto a necessidade do tratamento de efluentes bem como questões sanitárias e de saúde pública; nesse sentido uma linguagem simples e direta foi observada durante a elaboração.

A seguir serão apresentados os principais tópicos na elaboração junto a plataforma CANVA com o objetivo de alcançar o envolvimento dos discentes com relação a informações sobre a Educação Ambiental e adoção de comportamentos ambientalmente corretos que irão ser repassados à comunidade através da elaboração da cartilha educacional. 


\section{Discussão dos tópicos envolvidos na elaboração da cartilha}

$\mathrm{Na}$ Figura 4 que corresponde a página de capa da cartilha educacional, foram colocados o título da cartilha "Fossa Séptica e Filtro-anaeróbio: Conceitos e Dicas de Manutenção" com uma imagem que remete ao descarte de efluentes em águas superficiais.

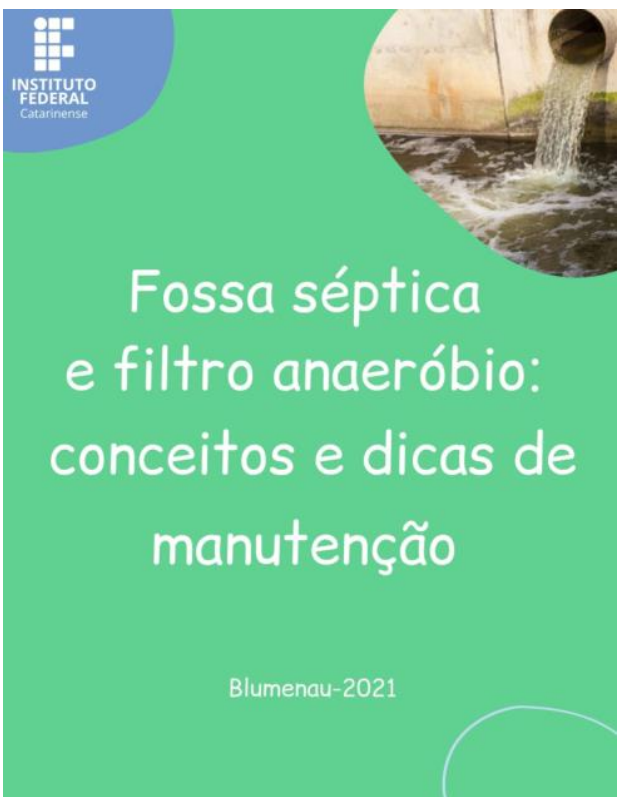

Figura 4: Página capa da Cartilha Educacional. Fonte: IFC et al., 2021

Na Figura 5 o tema é introduzido através de um questionamento "O que é o esgoto?"; conceituando o termo águas residuais bem como a origem e a composição do esgoto doméstico.

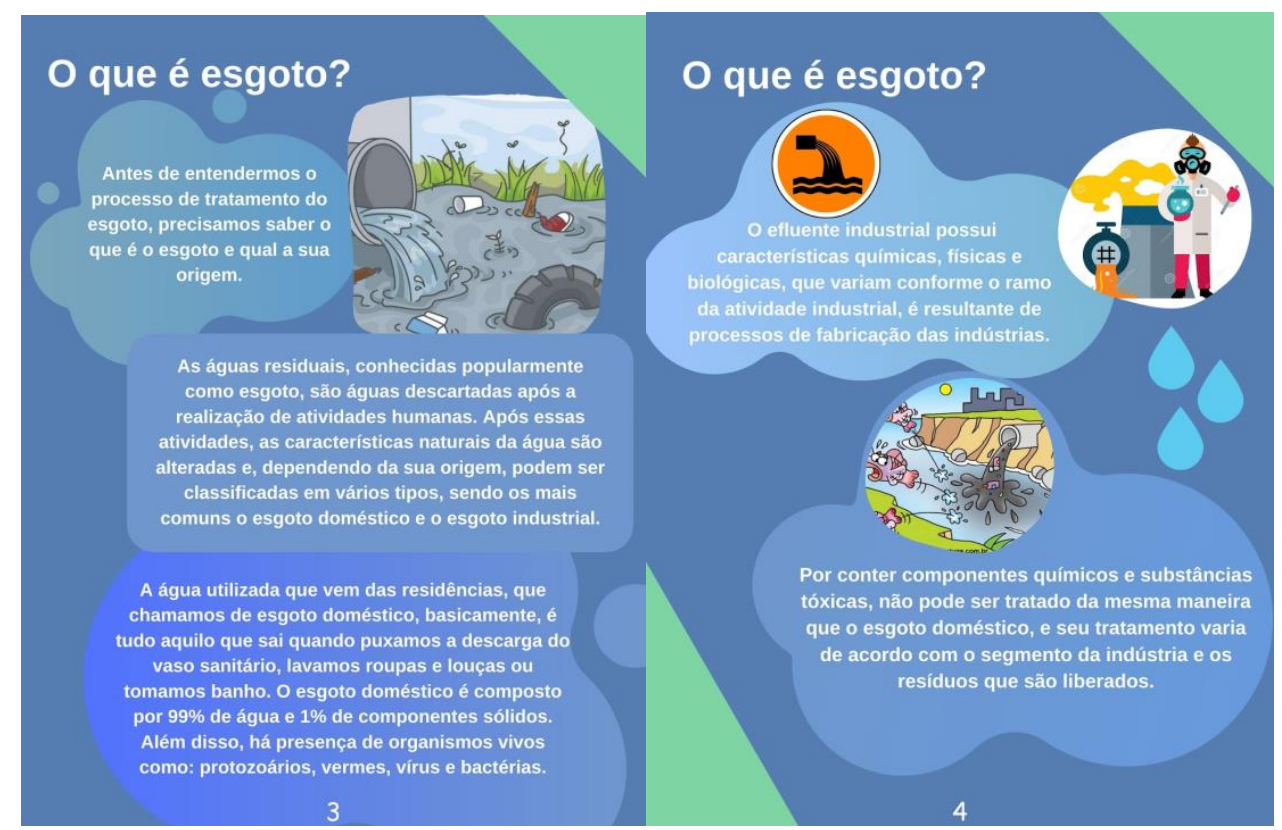


O esgoto doméstico é composto por água e uma pequena quantidade de componentes sólidos, no entanto a presença de organismos patogênicos justifica a necessidade de tratamentos de águas residuais. Na cartilha foi definido o que é o esgoto doméstico e esgoto industrial com suas diferentes características principalmente com relação aos componentes químicos e os diferentes processos de tratamento.

A Figura 6 apresenta a página da cartilha que contém o sistema fossa séptica-filtro e sumidouro. A figura da fossa séptica foi elaborada utilizando 0 aplicativo ACDLabs 8.0 versão livre, desenhado de forma didática com as etapas envolvidas durante o tratamento no sistema. Um sistema de tratamento do esgoto doméstico consiste em um processo de biodigestão envolvendo microorganismos, que são os responsáveis pela decomposição e redução da carga orgânica presente em grande quantidade no esgoto.

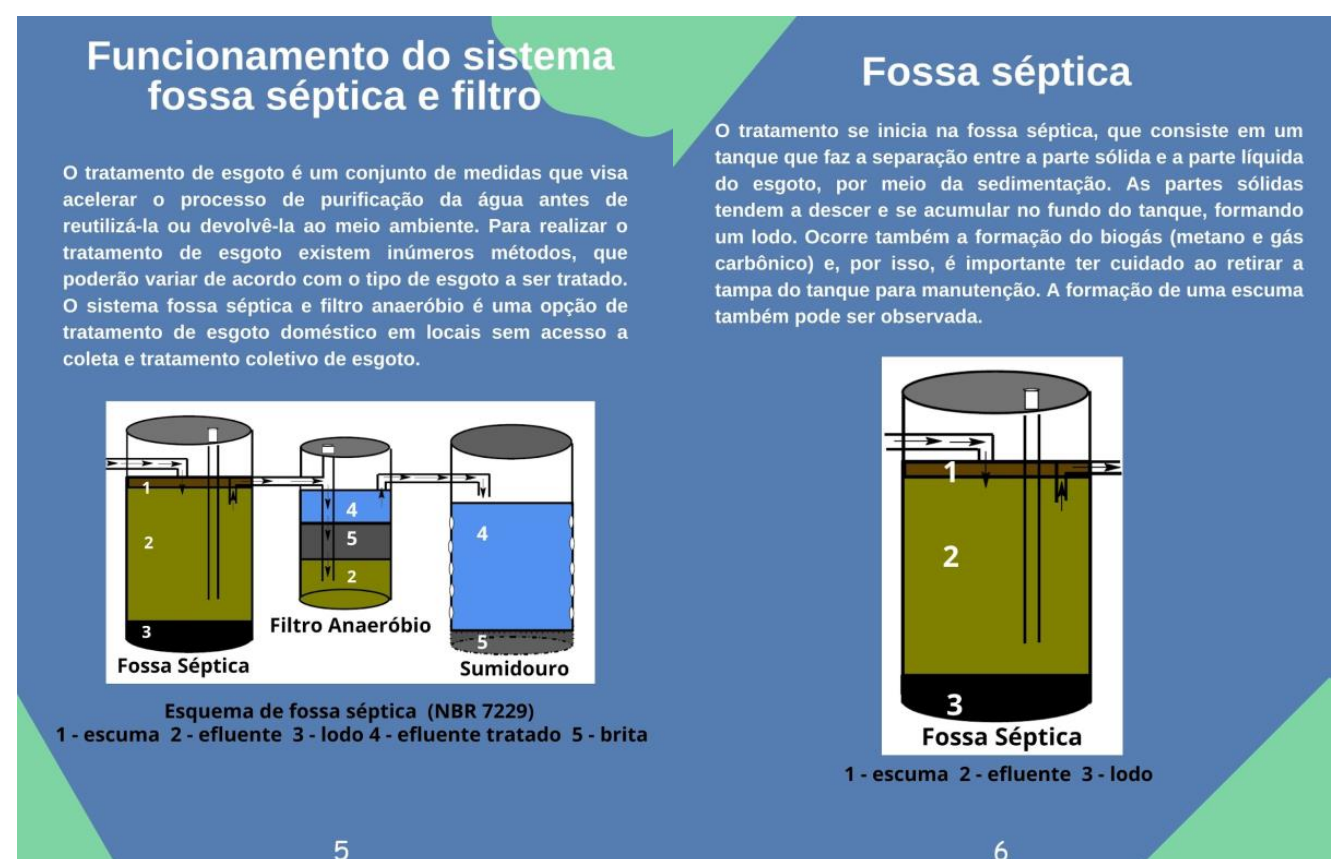

Figura 6: Página 5 e 6 da Cartilha Educacional. Sistema de funcionamento de fossa séptica. Fonte: IFC et al., 2021.

As etapas de filtração e drenagem do efluente tratado para o solo são identificadas, enfatizando o mecanismo envolvendo o tratamento do efluente bem como os processos envolvidos.

Na Figura 7 nas páginas 8 e 9 da cartilha, foram levantados os principais cuidados com relação a utilização e manutenção das fossas sépticas. A composição dos efluentes com relação ao descarte de reagentes químicos em excesso e óleos de cozinha influenciam no desempenho das fossas sépticas. 


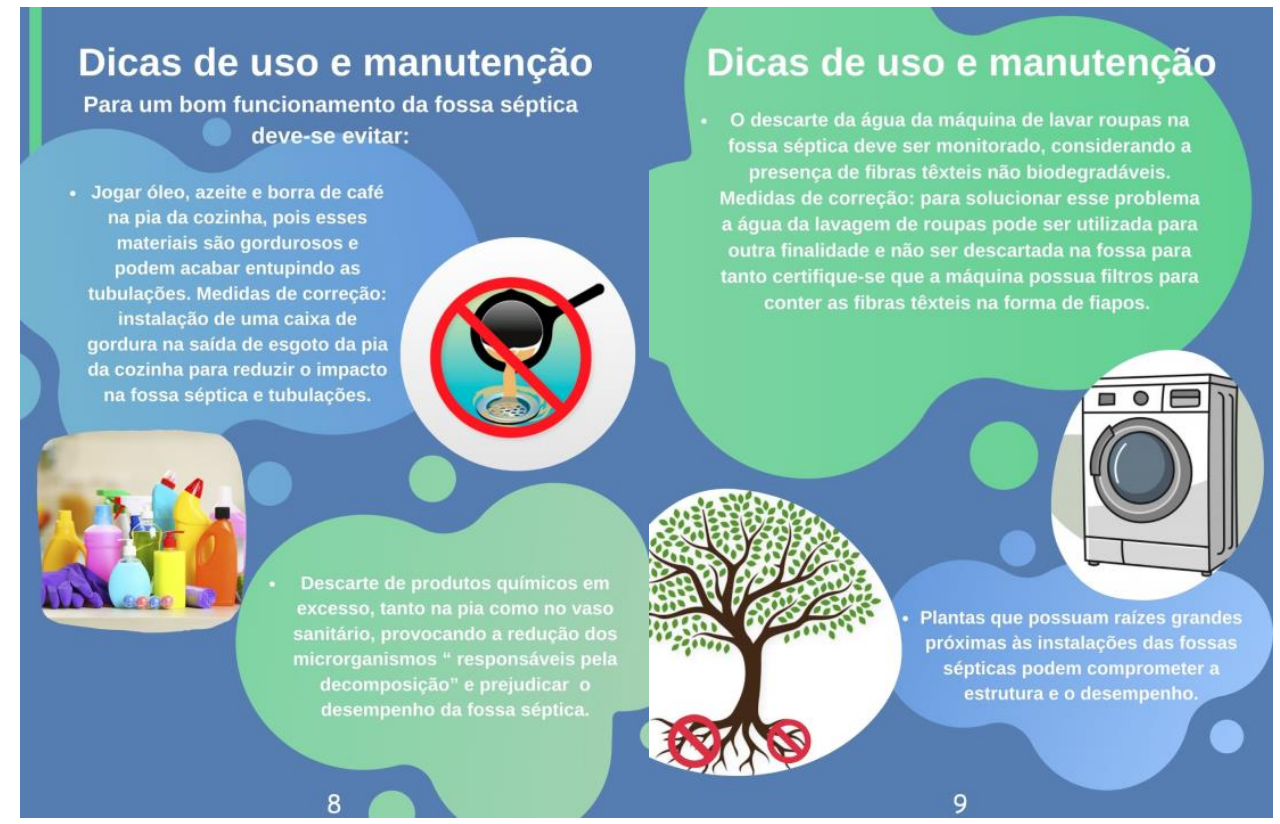

Figura 7: Página 8 e 9 da Cartilha Educacional. Dicas e manutenções de fossa séptica. Fonte: IFC et al., 2021.

Na Figura 8 das páginas 11 e 12 da cartilha destacou-se a importância para a saúde humana e a conservação do meio ambiente com relação às águas residuárias.

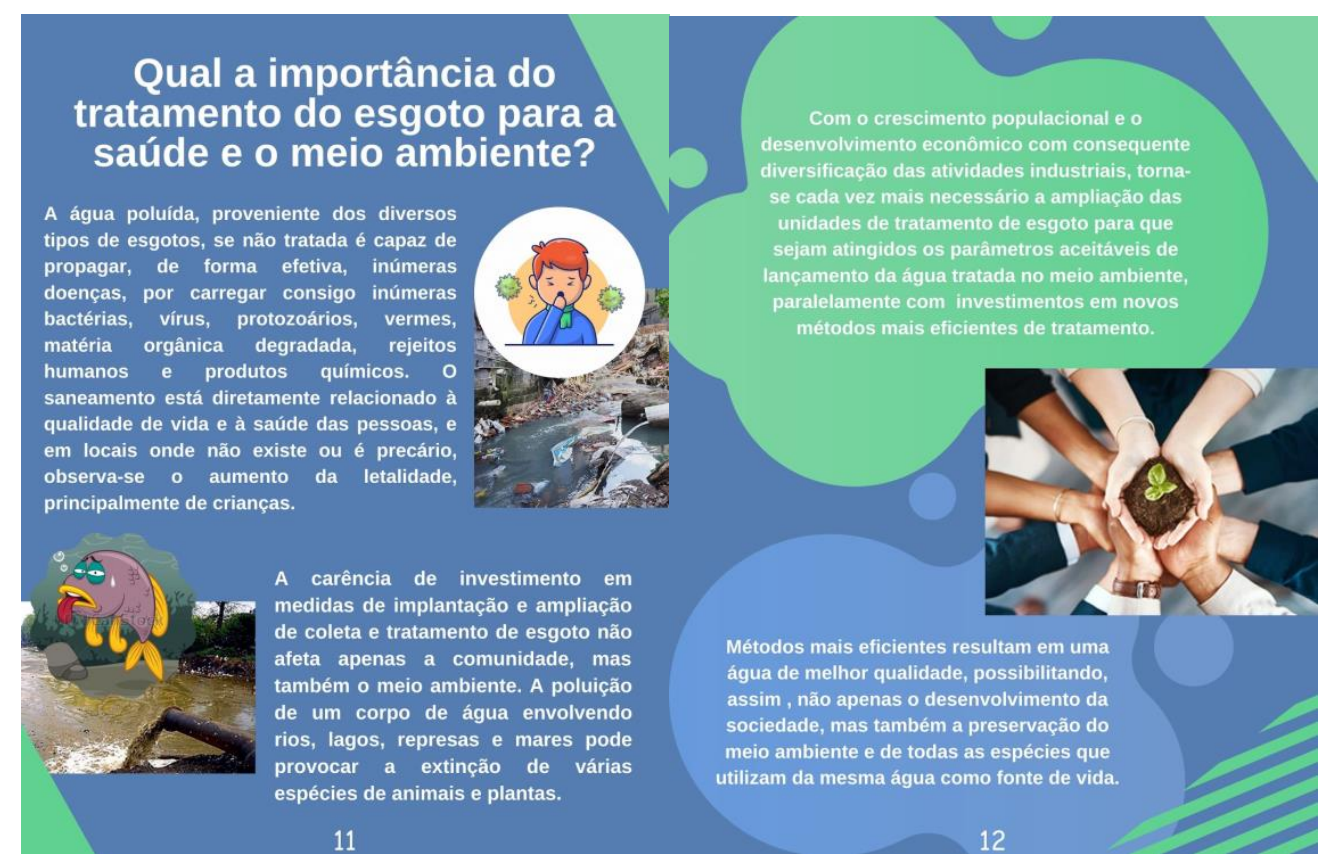

Figura 8: A importância para a saúde humana e a conservação do meio ambiente. Fonte: IFC et al., 2021. 
O saneamento está diretamente relacionado à qualidade de vida e à saúde das pessoas, e em locais com precariedade, observa-se o aumento da letalidade, principalmente de crianças. Com o crescimento populacional e 0 desenvolvimento econômico e a consequente diversificação das atividades industriais, torna-se cada vez mais necessário a ampliação das unidades de tratamento de esgoto para que sejam atingidos os parâmetros aceitáveis de lançamento da água tratada no meio ambiente, paralelamente com investimentos em novos métodos mais eficientes.

\section{Aplicação de um questionário com discentes do IFC e UFSC}

A cartilha é uma ferramenta auxiliar para os professores e profissionais da área de meio ambiente com relação à Educação Ambiental, conscientizando sobre a importância dos sistemas de tratamentos de esgotos e saúde pública. Nesse sentido, discussões e práticas de conscientização da cartilha foram feitas na disciplina de Educação Ambiental junto a UFSC no curso de licenciatura em química e estudantes do ensino médio do IFC da disciplina de Química.

$\mathrm{Na}$ disciplina de Educação Ambiental (UFSC) e Química (IFC) foram feitos quatro questionamentos, objetivando a interpretação da cartilha:

1. O que é o esgoto?

2. Como é o funcionamento de um sistema de fossa séptica, filtro e sumidouro?

3. Para um bom funcionamento de uma fossa séptica; como ser o uso e manutenção.

4. Qual a importância do tratamento de esgoto, para a saúde humana e para o meio ambiente?

As respostas ao questionário foram avaliadas segundo a interpretação da cartilha e enviadas via sistema Moodle sem identificação dos discentes. No universo de 80 alunos, houve coerência nas respostas segundo a interpretação dos temas abordados; observou-se que os discentes responderam de forma personalizada sem cópias dos textos, o que caracteriza uma excelente compreensão com relação aos conteúdos disponibilizados na cartilha.

\section{Conclusões e Considerações}

Projetos relacionados à participação das escolas são fundamentais para a formulação e execução de programas com atividades vinculadas a Educação Ambiental. Nesse sentido, a cartilha possui informações sobre saneamento básico em uma linguagem simples com a elaboração por discentes e orientação de docentes, através de um software de design gráfico.

A cartilha contribui com o Diagnóstico Amostral do município de Pomerode, considerando que a maioria da população utiliza o sistema de 
tratamento de esgoto doméstico com fossa séptica e filtro anaeróbio. A participação de estudantes da UFSC e IFC, para avaliar a aplicabilidade do material didático quanto a interpretação, caracterizou uma excelente compreensão com relação aos conteúdos disponibilizados na cartilha.

Como perspectivas futuras, a cartilha será divulgada para a comunidade através da prefeitura municipal de Pomerode via secretaria de educação e Programa Municipal de Educação Ambiental (Promea de Pomerode); contribuindo para a Educação Ambiental e a saúde pública através de uma linguagem acessível a estudantes e a comunidade.

\section{Referências}

ABNT - ASSOCIAÇÃO BRASILEIRA DE NORMAS TÉCNICAS - NORMA 13969, 2021 Tanques sépticos - Unidades de tratamento complementar e disposição final dos efluentes líquidos - Projeto, construção e operação. Disponível em: <https://www.abntcatalogo.com.br/norma.aspx?ID=3633>. Acesso em 12-03-2021.

ABNT - ASSOCIAÇÃO BRASILEIRA DE NORMAS TÉCNICAS - NORMA 7229, 2021 Projeto, construção e operação de sistemas de tanques sépticos. Disponível em: https://www.abntcatalogo.com.br/norma.aspx?ID=4522\#. Acesso em 12-032021.

BRASIL. Marco legal do saneamento - Lei № 14.026 de 15 de Julho de 2020. Atualiza o marco legal do saneamento básico e altera a Lei oㅜ 9.984, de 17 de julho de 2000, para atribuir à Agência Nacional de Águas e Saneamento Básico (ANA) competência para editar normas de referência sobre o serviço de saneamento. Brasília, 2020.

DA COSTA, C. C.; GUILHOTO, J.J.M. Saneamento rural no Brasil: impacto da fossa séptica biodigestora. Eng. Sanit. Ambiental. Rio de Janeiro, 2014, Edição especial pp 51-60.

DA SILVA REIS, N.S.; SANTOS, P.V.C. J. Caracterização das condições de manutenção e dos usos da zona costeira do município de São Luís (MA): A Educação Ambiental como alternativa de amenização de impactos. Revista Brasileira de Educação Ambiental, v.15, n.5, 2020. pp 333-344.

DE VICQ, R.; PRAÇA LEITE, M. G. Avaliação da implantação de fossas sépticas na melhoria na qualidade de águas superficiais em comunidades rurais. Eng Sanit Ambient. Rio de Janeiro, 2014. pp 411-416.

EMBRAPA - EMPRESA BRASILEIRA DE AGROPECUÁRIA. Como montar e usar a fossa séptica modelo Embrapa: cartilhas adaptadas ao letramento do produtor. Brasília, 2014.

FOCESI, P. Educação Ambiental, Qualidade de Vida e Sustentabilidade. Saúde e Sociedade. São Paulo.1998. pp 19-31. 
FUNASA, FUNDAÇÃO NACIONAL DA SAÚDE / MINISTÉRIO DA SAÚDE. Manual de Saneamento. Brasília, 2004.

FURB - FUNDAÇÃO UNIVERSIDADE REGIONAL DE BLUMENAU Pomerode Relatório Final: Diagnóstico Amostral dos Sistemas Individuais de Tratamento de Esgoto Doméstico. Disponível: $<$ https://static.fecam.net.br/uploads/1534/arquivos/1276812 Relatorio Pomero de.pdf $>$. Acesso em 12-03-2021.

IBGE - INSTITUTO BRASILEIRO DE GEOGRAFIA E ESTATÍTICA. Disponível em: <https://www.ibge.gov.br/cidades-e-estados/sc/pomerode.html. Acesso em 12-03-2021>. Acesso em 12-03-2021.

IFC - INSTITUTO FEDERAL CATARINENSE. Fossa Séptica e Filtroanaeróbio: Conceitos e Dicas de Manutenção. Disponível em: $<$ http://blumenau.ifc.edu.br/noticias/2021/06/09/cartilha-ensina-manutencao-defossas-e-filtros-anaerobicos >. Acesso em 15-06-2021.

MARTINS, A.B.C.; ROCHA J.P.; DE SANTANA C.G. Análise dos impactos causados pelo lançamento de efluentes domésticos não tratados e sua relação com a capacidade de autodepuração de um corpo hídrico. Revista do Centro de Estudos em Desenvolvimento Sustentável. Maranhão, 2018.

MINISTÉRIO DA SAÚDE / SECRETARIA DE VIGILÂNCIA EM SAÚDE. Saúde Brasil 2018: Uma análise da situação de saúde e das doenças e agravos crônicos: desafios e perspectivas. Brasília, 2019.

SNIS - SISTEMA NACIONAL DE INFORMAÇÕES SOBRE SANEAMENTO. 24ํㅡㅁ Diagnóstico dos Serviços de Água e Esgotos - Brasília, 2019.

TISCHER; V. Planos municipais de saneamento básico: Estratégias de Educação Ambiental. Revista Brasileira de Educação Ambiental, V.11, n.2, 2016, pp 203-215. 